\title{
Role of endoscopic ultrasound in the diagnosis of pancreatic neuroendocrine neoplasms
}

\author{
Tatsuya Ishii*, Akio Katanuma, Haruka Toyonaga, Koki Chikugo, Hiroshi Nasuno, Toshifumi \\ Kin, Tsuyoshi Hayashi and Kuniyuki Takahashi \\ Center for Gastroenterology, Teine Keijinkai Hospital, Sapporo, Hokkaido, Japan \\ * Correspondence: ttyisi141@outlook.com; Tel.: +81-11-681-8111; FAX: +81-11-685-2967
}

\begin{abstract}
Although pancreatic neuroendocrine neoplasms (PNENs) are relatively rare tumors, their number is increasing with advances in diagnostic imaging modalities. Even small lesions that are difficult to detect using computed tomography or magnetic resonance imaging can be detected with endoscopic ultrasound (EUS). Contrast-enhanced EUS is useful, and not only diagnosis but also malignancy detection have become possible by evaluating the vascularity of tumors. Pathological diagnosis using EUS with fine-needle aspiration (EUS-FNA) is useful when diagnostic imaging is difficult. EUS-FNA can also evaluate the grade of malignancy. Pooling the data of the studies which compared the PNENs grading between EUS-FNA samples and surgical specimen, the concordance rate was $77.5 \%$ ( $\kappa$-statistic: $0.65,95 \%$ confidence interval $=0.59-0.71, \mathrm{P}<0.01)$. EUS is a particularly important modality for the treatment of PNENs.
\end{abstract}

Keywords: Endoscopic ultrasound; Pancreatic tumor; pancreatic neuroendocrine neoplasms

\section{Introduction}

Pancreatic neuroendocrine neoplasms (PNENs) are relatively rare tumors that account for $2 \%-$ $3 \%$ of all pancreatic tumors. However, the number of reported cases has been increasing, mainly because of advances in various diagnostic imaging modalities. Among them, endoscopic ultrasound (EUS) has superior sensitivity for detecting PNENs compared with computed tomography (CT) and magnetic resonance imaging (MRI). With its high resolution and when performed by experienced hands, EUS can detect focal lesions as small as $2-5 \mathrm{~mm}$ [1]. Tissue acquisition using EUS with fineneedle aspiration (EUS-FNA) is essential for making a diagnosis and treatment decisions. Here, we review the current literature with respect to the role of EUS in the diagnosis of PNENs.

\section{EUS for detecting PNENs}

EUS enables detailed observation of the entire pancreas with high tissue resolution, without being affected by the gastrointestinal tract or subcutaneous fat (Figure 1a). In a systematic review, Puli et al. reported that EUS has a sensitivity of $87.2 \%$ and a specificity of $98.0 \%$ for detecting PNENs [2]. Manta et al. reported that CT failed to detect $68.4 \%$ of PNENs $<10 \mathrm{~mm}$ and a further $15 \%$ of PNENs $\leq 20 \mathrm{~mm}$ in diameter [3]. Moreover, it has been reported that the sensitivity of CT is reduced for small lesions $<1 \mathrm{~cm}$ and that $91 \%$ of PNENs that are difficult to detect using multidetector-row CT can be detected with EUS [4]. James et al. reported in a meta-analysis that preoperative EUS consistently increased the overall PNEN detection rate by $>25 \%$ after CT scan, with or without additional investigative modalities such as MRI or ultrasound [5]. Thus, EUS is an essential modality in the diagnosis of small PNENs. 


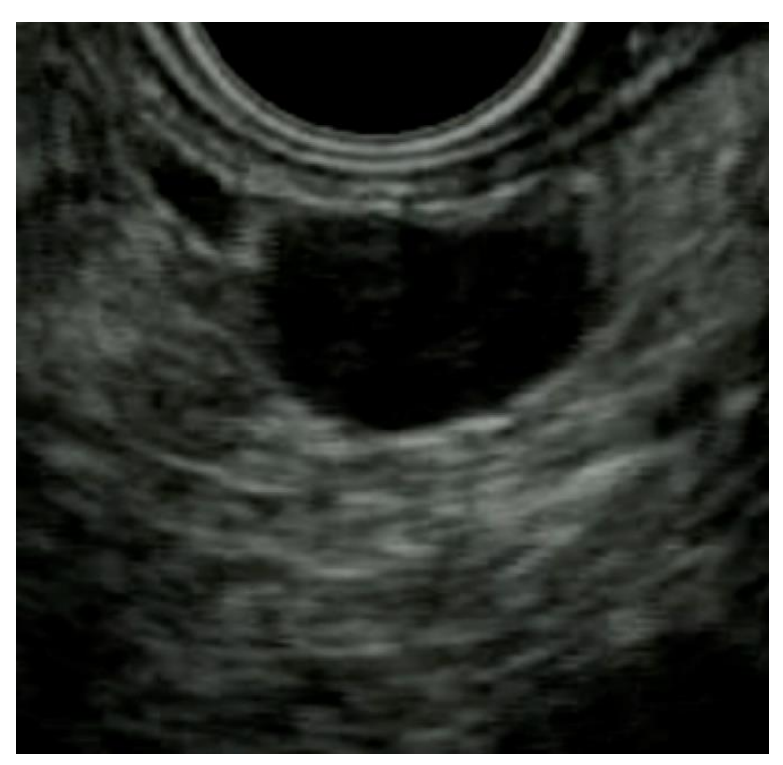

a

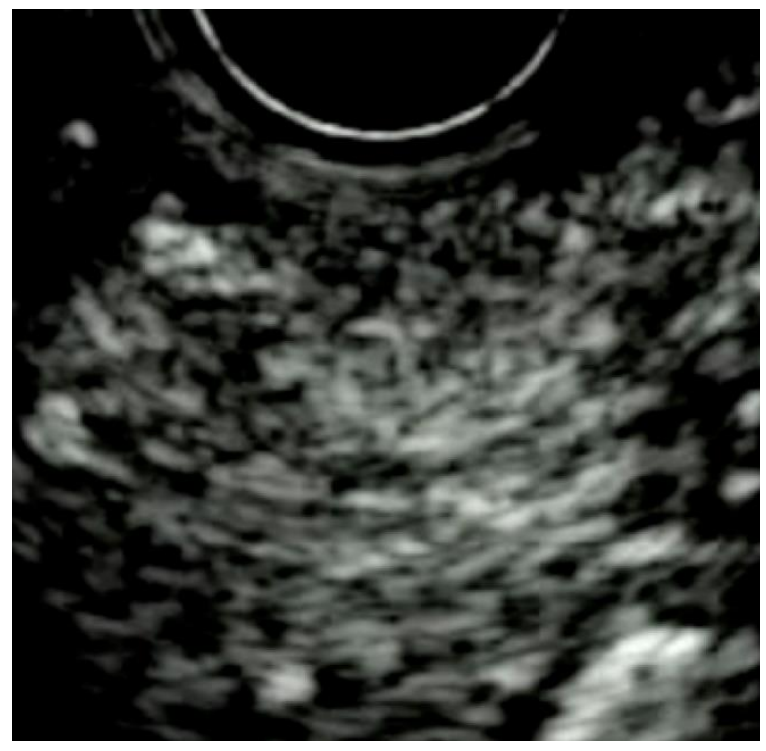

b

Figure 1. (a) B-mode endoscopic ultrasound (EUS): a circular hypoechoic mass in the body of the pancreas. (b) Contrast-enhanced EUS: the mass shows early enhancement compared with the surrounding pancreatic parenchyma.

\section{Precautions for EUS in functional PNENs}

Nonfunctional PNENs are often asymptomatic and not detected until the tumor has grown large enough to cause a mass effect, or until they metastasize. However, because functioning PNENs secrete hormones that cause symptoms, their presence is suspected earlier and a diagnosis is often made while the lesions are small. Functioning tumors comprise 34.5\% of all PNENs [6]. Of the functional tumors, insulinomas are the most common $(20.9 \%)$, followed by gastrinomas $(8.2 \%)$, glucagonomas (3.2\%), vasoactive intestinal peptide-producing tumors $(0.6 \%)$, and somatostatinomas $(0.3 \%)$. Insulinomas tend to be smaller than other functioning PNENs, owing to the dramatic clinical syndrome caused by insulin secretion. Insulinomas are usually small at diagnosis, with $90 \%$ of tumors being $<2 \mathrm{~cm}$ in diameter and $40 \%$ being $<1 \mathrm{~cm}$ [7]. Most insulinomas occur in the pancreas, and these tumors are evenly distributed throughout the pancreatic head, body, and tail [8]. Approximately $2 \%-10 \%$ of patients with insulinomas have multiple tumors, particularly those with multiple endocrine neoplasia type 1 (MEN1) [7,9]. Thus, it is important to evaluate the entire pancreas in detail when observing insulinomas with EUS. Although insulinomas are usually sporadic, they account for $10 \%-30 \%$ of functioning PNENs in patients with MEN1. MEN1 coexists in $4 \%-5 \%$ of insulinomas [8].

Gastrinomas often arise in the gastrinoma triangle, an area bounded by the junctions of the cystic duct and common bile duct superiorly, the second and third portions of the duodenum inferiorly, and the neck and body of the pancreas medially[7]. They are more common in the duodenum than in the pancreas, and approximately $80 \%$ of sporadic lesions and $90 \%$ of lesions associated with MEN1 originate from the duodenum. Previously, the pancreas was believed to be the most common location; however, many of these masses may have been peripancreatic nodal metastases from small duodenal tumors. Pancreatic gastrinomas have an average diameter of 3-4 cm, and most are located in the pancreatic head. Duodenal gastrinomas are usually $<1 \mathrm{~cm}$ in diameter and are often multicentric, especially in patients with MEN1 [7]. Under EUS, it is necessary to carefully observe not only the pancreatic head but also the duodenal wall. Although most gastrinomas sporadically arise, they are the most common functioning PNENs in patients with MEN1 $(20 \%-25 \%$ of all gastrinomas occur in these patients). However, the recent report shows that small PNETs in patients with MEN1 grow more slowly than previously thought, the necesity of EUS surveillance for the MEN1 patient with only small asymptomatic PNETs may be reduced [10]. 
As mentioned above, because PNENs and MEN1 are related, we must not forget to check for coexistence of MEN1 in PNEN patients (Figure 2a-d).

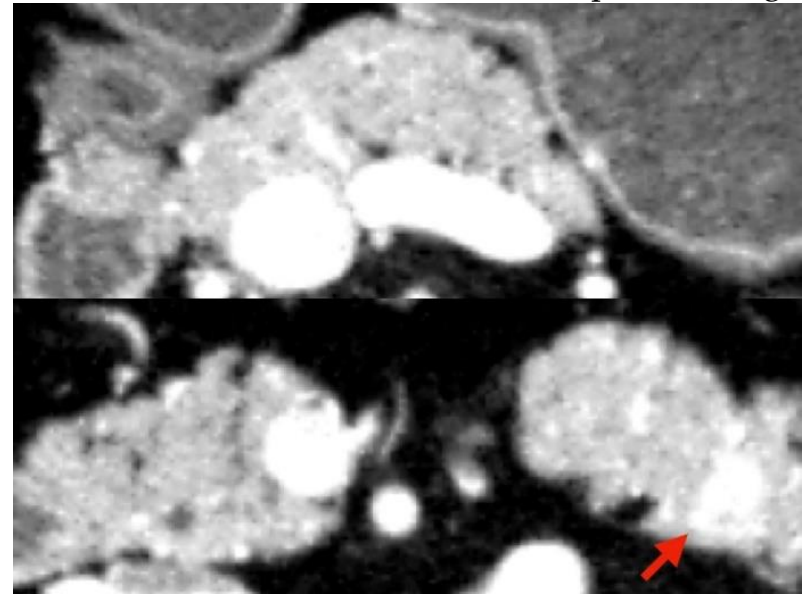

a

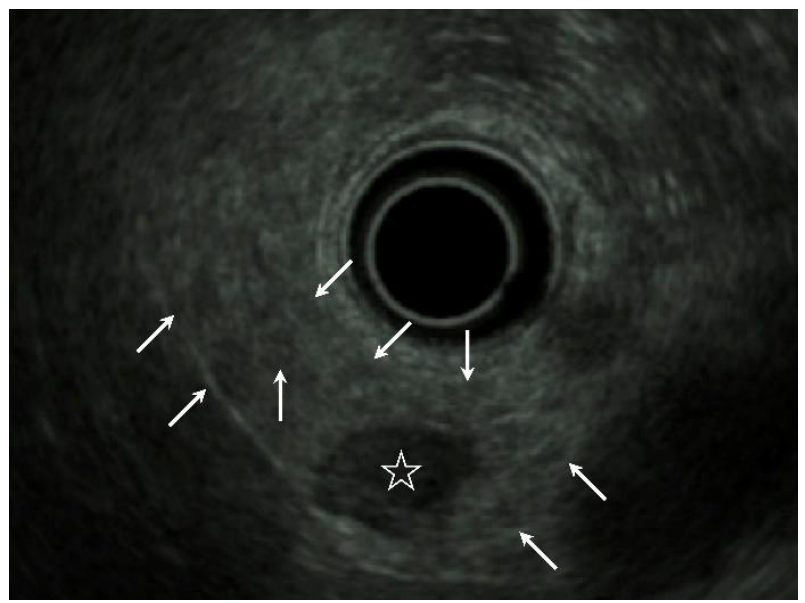

C

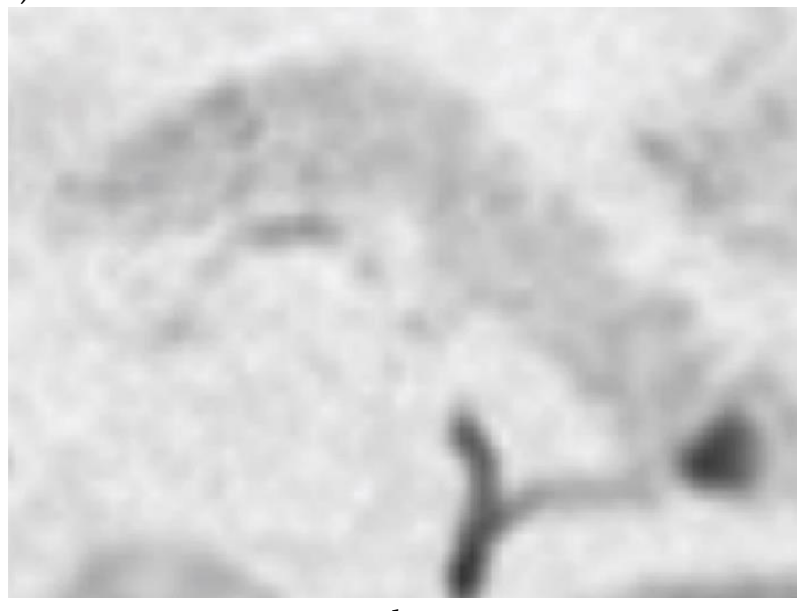

b

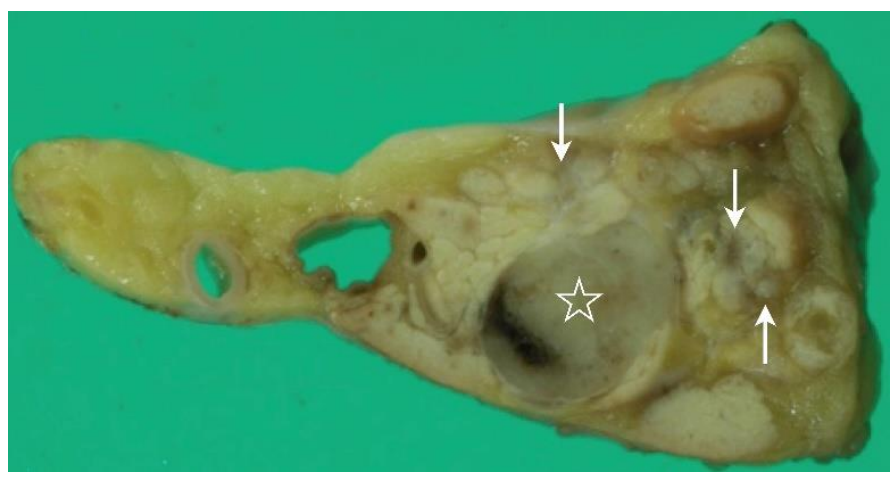

d

Figure 2. (a) Contrast-enhanced computed tomography (CT): a mass lesion with early hyperenhancement is seen in the tail of the pancreas (red arrow), but there are no other obvious lesions. (b) Diffusion-weighted magnetic resonance imaging (MRI): the mass in the pancreatic tail shows reduced diffusion. (c) Endoscopic ultrasound (EUS): in addition to the mass (疎) revealed by CT/MRI, many small hypoechoic masses are observed (white arrow). (d) Resected specimen: the main lesion ( $(\mathcal{2})$ is an 11-mm neuroendocrine neoplasm (NEN) G1, but multiple tumors with a diameter of 1-3 mm are observed in the surrounding pancreas (white arrow). They are multiple NENs associated with multiple endocrine neoplasia type 1 (MEN-1).

\section{Role of contrast-enhanced EUS (CE-EUS)}

CE-EUS is useful for the evaluation of pancreatic disease because it permits the observation of the hemodynamics of masses in real time. This technique is based on the fact that microbubbles in contrast agents are disrupted by ultrasound waves, producing signals that are detected by the ultrasound imager. Because typical PNENs have abundant blood vessels, these tumors show hypervascular contrast in the early phase, persisting until the delayed phase (Figure 1b). CE-EUS has a high sensitivity (78.9\%-95.1\%) and a high specificity (98.7\%) in the identification of PNENs [11-12].

Ishikawa et al. reported that a heterogeneous ultrasonographic texture indicates a malignant disease [11]. Furthermore, Palazzo et al. reported that contrast-enhanced harmonic EUS (CH-EUS) is accurate in predicting an aggressive tumor behavior by evaluating the heterogeneous patterns of PNENs, with a sensitivity of $86 \%$ and a specificity of $96 \%$ [13]. Takada et al. reported that CH-EUS with time-intensity curve analysis is useful for PNEN diagnosis and grading [14]. 
CE-EUS plays an important role in finding a specific site within a lesion that would be more suitable for EUS-FNA. Identification of hypervascular sites in such lesions may help avoid sampling rich fibrous areas [15].

\section{Features of EUS findings in PNENs}

On EUS examination, PNENs typically appear as well-rounded, hypoechoic lesions with a homogeneous pattern and clear regular margins (Figure 1a,b). However, because PNENs expansively grow, they may cause cystic degeneration and calcification as their size increases. In these cases, PNENs often present a heterogeneous pattern.

\subsection{Cystic degeneration}

The most common cause of cystic degeneration is tumor bleeding, whereas tumor necrosis is rarely the cause. Cystic degeneration is mostly found in well-differentiated PNENs (Figure 3a-e). The frequency is $10 \%-17 \%$ of all PNENs, and the larger the tumor, the higher the rate of cystic degeneration [16]. Gaujoux et al. found no association between cystic degeneration and tumor malignancy [16]. Cystic degeneration is visualized as a low absorption area on contrast CT, and is recognized as a nonechoic area on B-mode EUS and as an avascular area on CE-EUS. If the cysts become larger, the imaging findings will be similar to those of serous cystic neoplasms, and differentiation is necessary [17]. In EUS diagnosis, it is important to find the solid tumor part of the cyst margin as a wall thickening or protrusion. Sensitivity of EUS-FNA for cystic PNENs is lower than solid PNENs [18]. The cyst wall and septations should be targeted with FNA to maximize cytologic diagnosis [19].

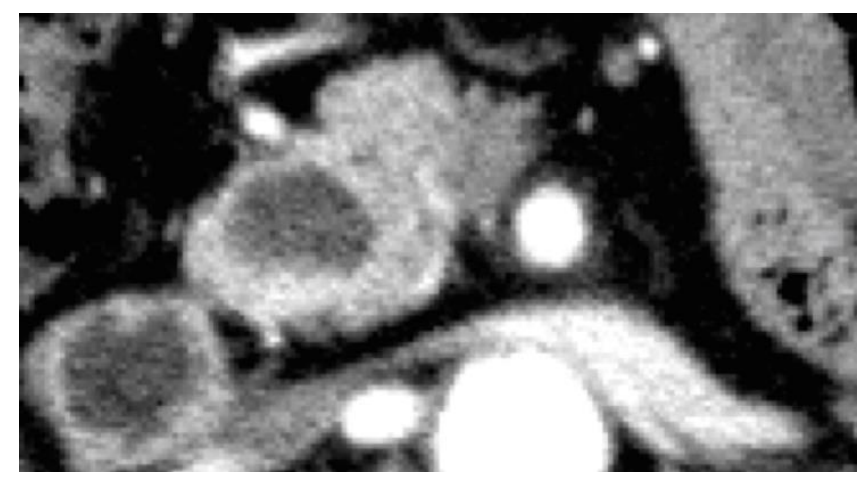

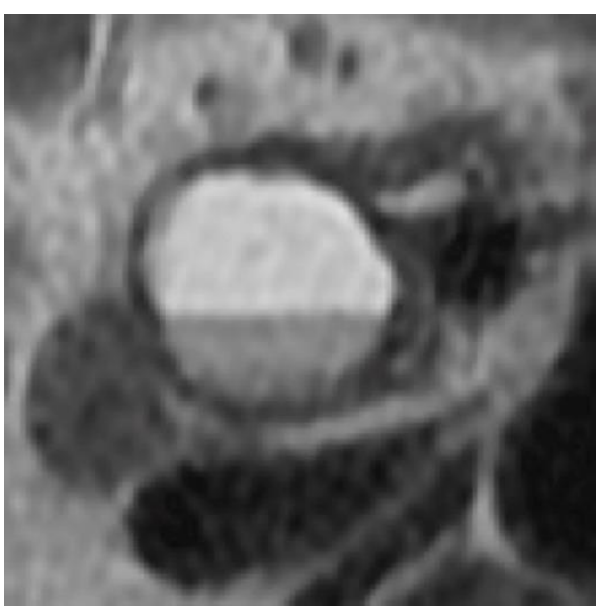

b

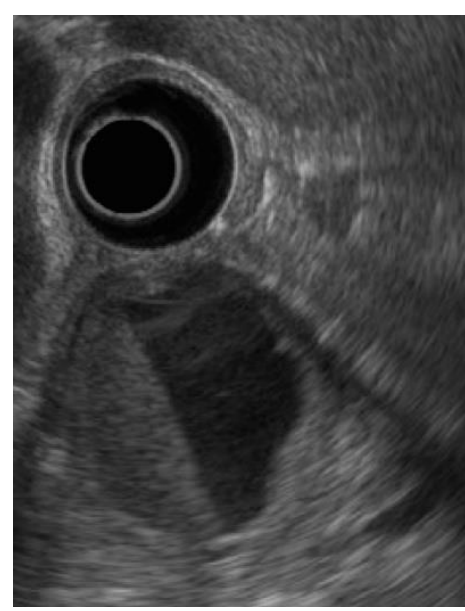

C 




d

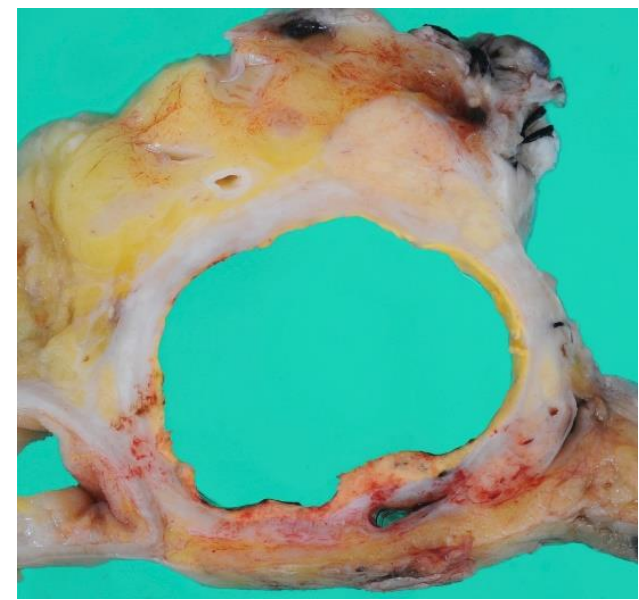

e

Figure 3. (a) Contrast-enhanced computed tomography (CT): a cystic lesion is seen on the pancreatic head. (b) Magnetic resonance imaging: fluid-fluid level formation is shown. (c) B-mode endoscopic ultrasound (EUS): a cystic lesion with fluid-fluid level formation and a thickened wall. (d) Contrastenhanced EUS: the wall is hyperenhanced compared with the surrounding pancreatic parenchyma.

(e) Resected specimen: neuroendocrine neoplasm G1.

\subsection{Pancreatic duct stricture}

Large PNENs may press the main pancreatic duct (MPD), resulting in stricture or obstruction; however, even small PNENs may cause MPD stenosis (Figure 4). It has been reported that pancreatic duct stenosis is caused not by physical compression by the tumor but by serotonin-induced stromal fibrosis [20]. 


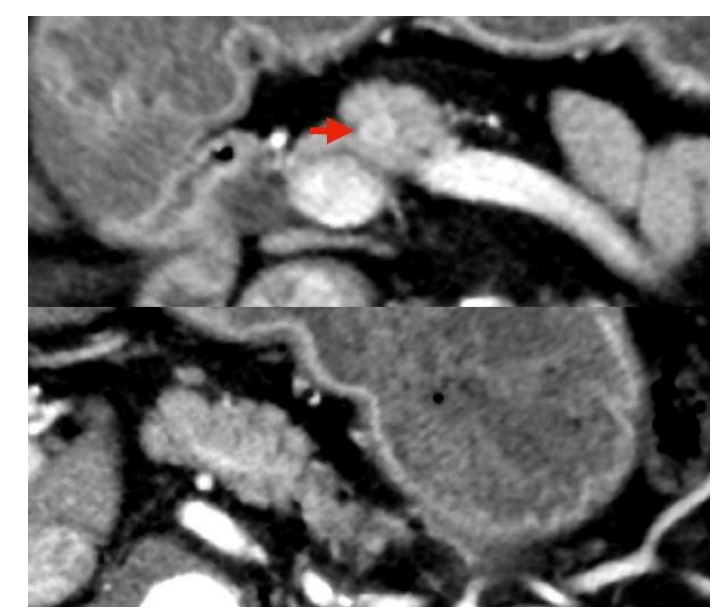

a

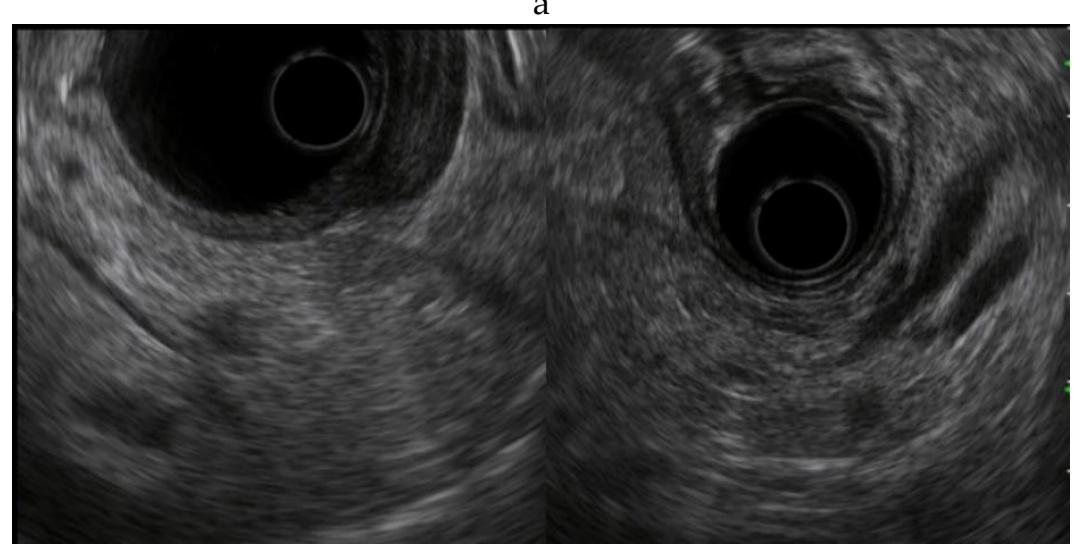

c

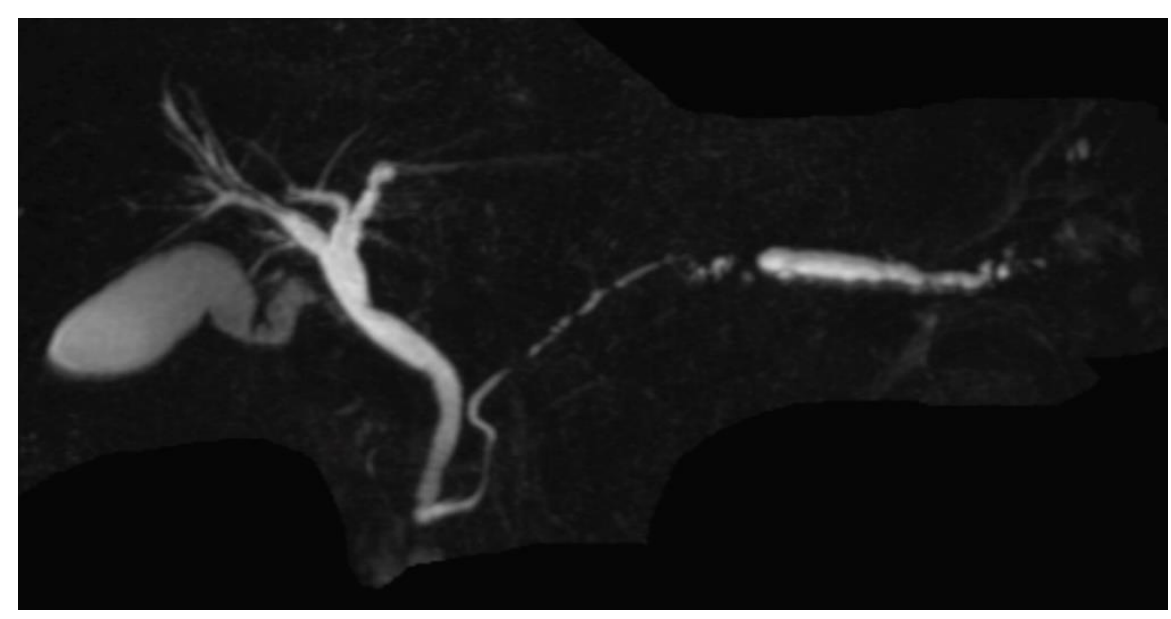

b

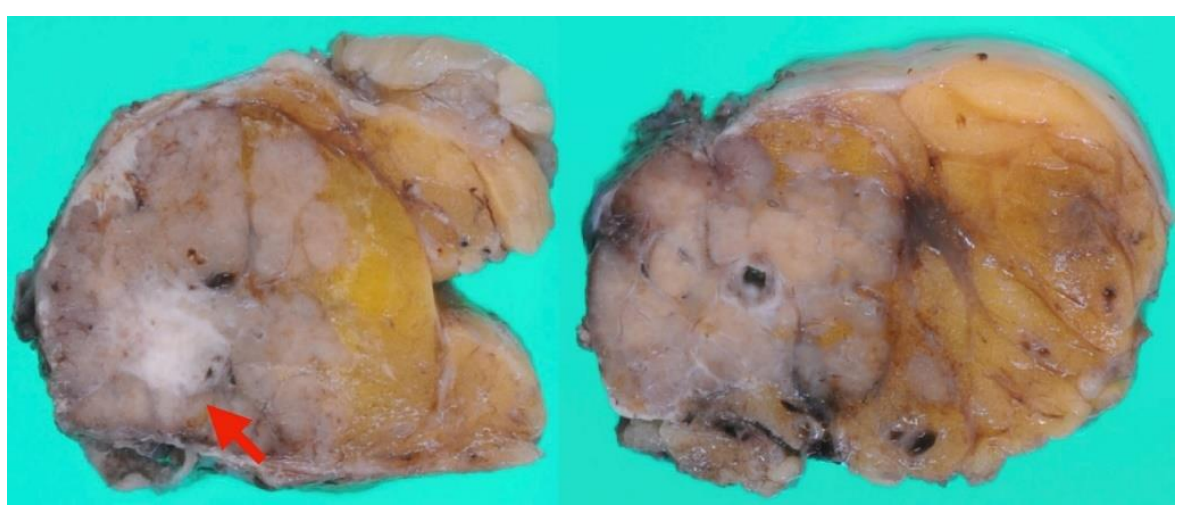

d

Figure 4. (a) Contrast-enhanced computed tomography (CT): a mass lesion with early hyperenhancement is seen in the pancreatic body (red arrow), but there are no other obvious lesions. (b) Magnetic resonance imaging: the main pancreatic duct (MPD) in the pancreatic body is extensively narrowed, and the caudal duct is dilated. (c) Endoscopic ultrasound (EUS): a circular hypoechoic mass in the pancreatic body. Pancreatic duct stenosis is observed even in the absence of mass. (d) Resected specimen: 6-mm neuroendocrine neoplasm G1 (red arrow), serotonin positive, with surrounding extensive fibrosis. 


\subsection{Intraductal invasion of the MPD}

Intraductal growth of neuroendocrine tumors (NETs) is rare. It has been reported that tumors with intraductal growth are highly malignant and have a poor prognosis [21]. Intraductal invasion shows early contrast enhancement, with a decrease during the delayed phase on CT images, and this pattern is helpful for differentiating pancreatic NETs from pancreatic ductal adenocarcinomas [21]. Under EUS, if the tumor is extending to the MPD, malignancy needs to be considered. Acinar cell carcinomas and solid pseudopapillary neoplasms (SPNs) may also show intraductal growth, and these tumors may be difficult to differentiate from PNENs.

\section{Features of imaging findings in PNEN G3 and pancreatic neuroendocrine carcinoma (PNEC)}

Although there are histopathological differences between PNEN G3 and PNEC, their imaging findings are similar, and both of these tumors show similarities to normal pancreatic cancer (pancreatic ductal carcinoma) and pancreatic acinic cell carcinoma (Figure 5) [22]. It has been reported that tumor blood flow correlates with prognostic factors, and the lower the vascularity, the the more advanced the malignancy [23]. Histologically, the tumor does not have a capsule and grows invasively. Moreover, the tumor has abundant fibrous stroma, resulting in hypovascularity. The tumor margins are irregular, unclear, and hypovascular, and internal necrosis of the tumor and the above-mentioned pancreatic duct stenosis and intraductal extension occur at a high frequency. The necrotic area is recognized as a nonechoic area on B-mode EUS and as an avascular area on CE-EUS. It is difficult to distinguish using diagnostic imaging alone, and pathological examination is required.

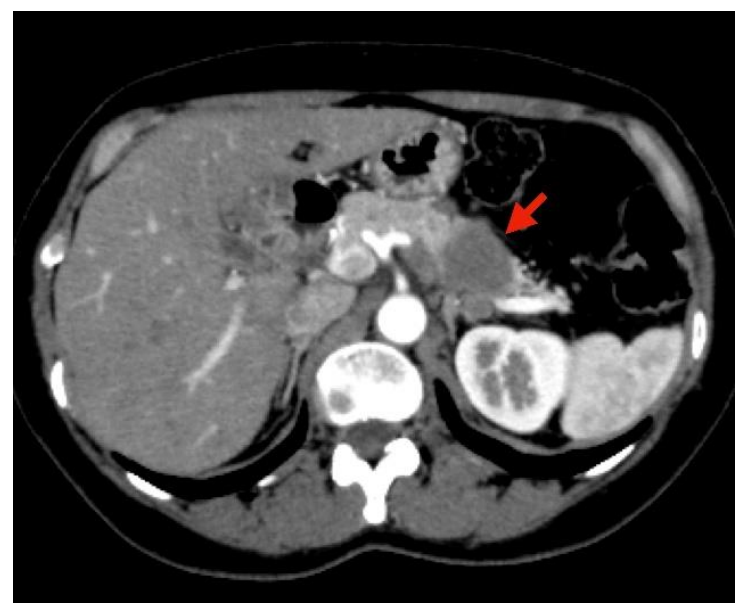

a

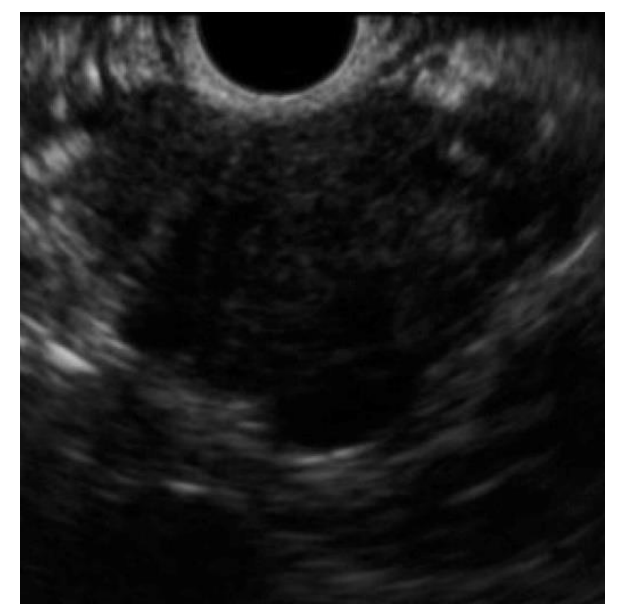

b

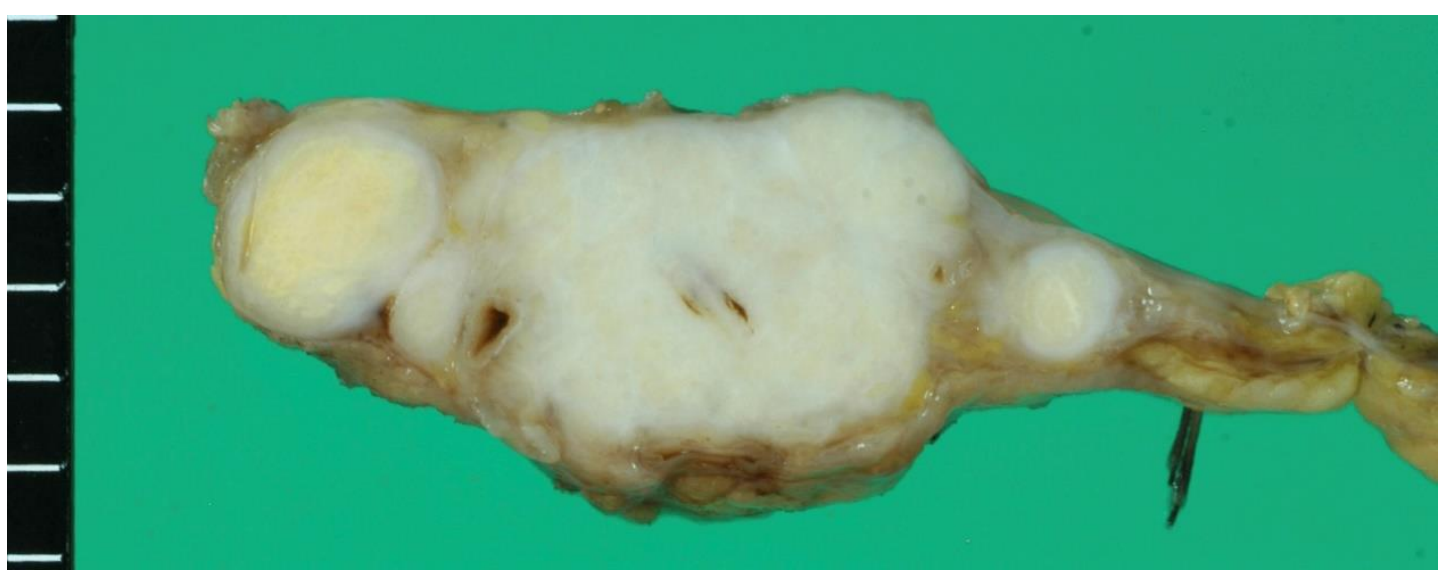

C

Figure 5. (a) Contrast-enhanced computed tomography (CT): an ill-defined mass (arrow) with a hypovascular enhancement pattern. The dilated pancreatic duct is notable. (b) Endoscopic ultrasound 
(EUS): irregular margins, unclear boundaries, and heterogeneous hypoechoic masses are shown. (c) Resected specimen: Ki-67 > 20\%, neuroendocrine neoplasm G3.

\section{Tumors that need to be differentiated from PNENs}

\section{1. $S P N$}

SPN is mostly seen in young female patients, and most SPNs have a good prognosis [24]. SPNs usually show similar characteristics to PNENs, such as being solid lesions with a round shape and clear borders within the pancreas, cystic degeneration, and cystic calcification (Figure 6a-d). A study comparing the EUS findings of SPNs and PNENs reported that more SPNs had a cystic component and more PNENs had hypervascularity [25]. However, differentiation is often difficult, and pathological diagnosis with immunostaining using EUS-FNA is useful for the diagnosis [26-27].

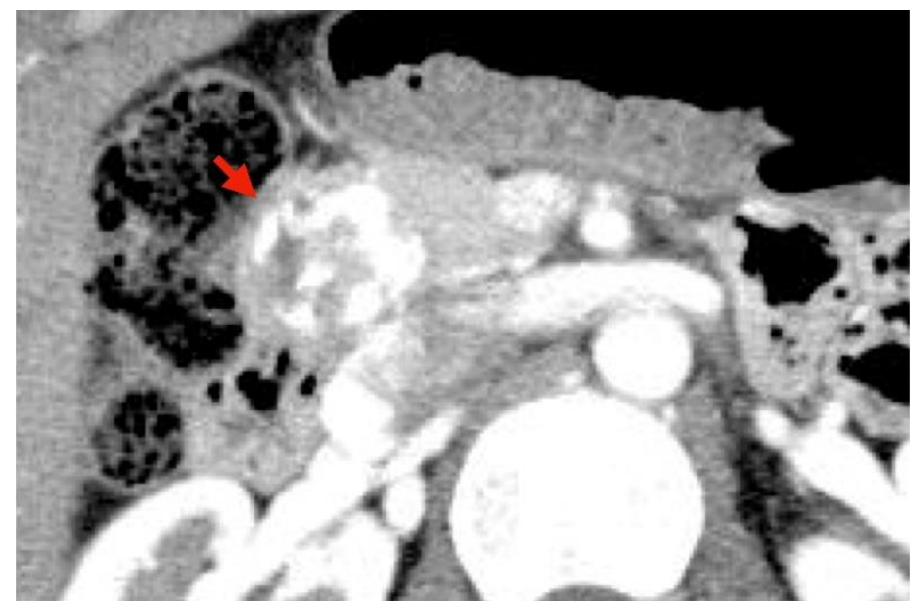

a

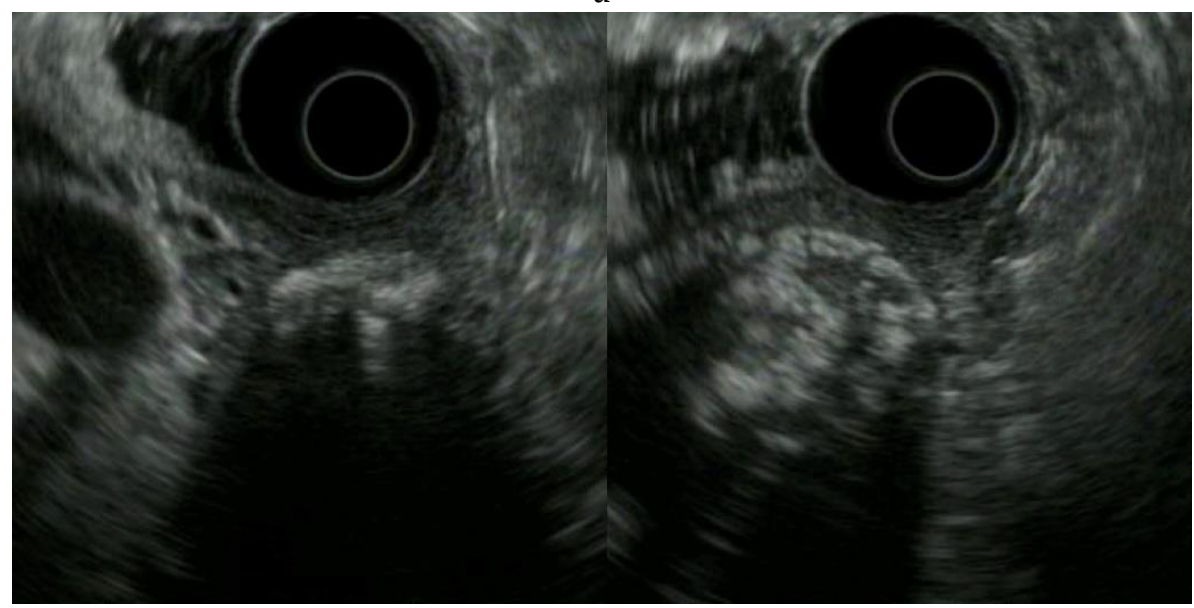




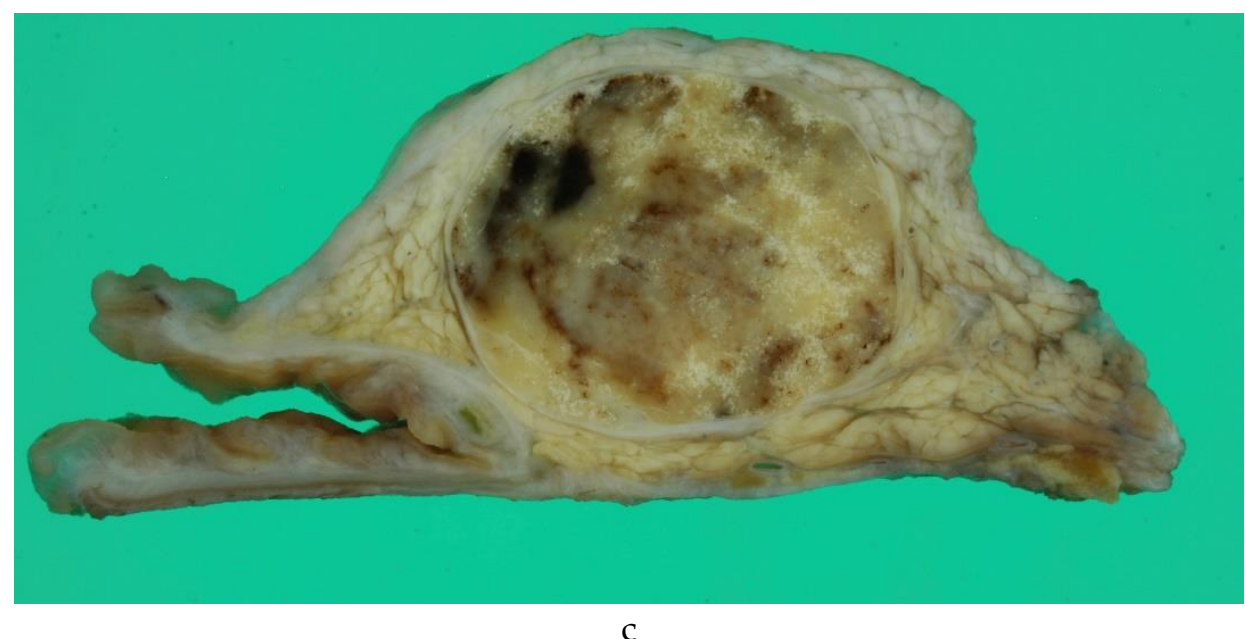

Figure 6. (a) Contrast-enhanced computed tomography (CT): a tumor (arrow) with calcification components is shown at the pancreatic head. (b) Endoscopic ultrasound (EUS): a well-defined mass with a heterogeneous appearance and peripheral rim calcification with posterior acoustic shadowing. (c) The imaging findings suggest a solid pseudopapillary neoplasm, but pathologically, it is a neuroendocrine tumor G1.

\subsection{Serous cystic neoplasm (SCN)}

As mentioned above, cystic degenerated PNENs show imaging findings similar to those of macrocystic-type SCNs. In addition, solid-type SCNs show imaging findings of hypervascularity and a solid appearance, and needs to be differentiated from typical PNENs $[17,28]$. Nonenhanced CT and MRI with T2-weighted imaging and apparent diffusion coefficient maps could be helpful for differentiation because the cystic area of PNENs shows bleeding, whereas SCNs are different in that they store serous fluid. However, these tumors are difficult to distinguish using EUS alone.

\subsection{Intrapancreatic accessory spleen (IPAS)}

IPAS is a congenital ectopic spleen that mostly occurs in the pancreatic tail. IPAS appears as a well-defined circular mass and is hypervascular with blood flow similar to that of the spleen [29-30]. Although it is difficult to distinguish IPAS from PNEN with EUS alone, Bhutani et al. reported that careful observation shows a bridge sign connecting the lesion and the spleen [31]. In T2-weighted images of superparamagnetic iron oxide MRI, IPAS has a low signal similar to that of the spleen, thus allowing it to be distinguished from PNENs. The usefulness of histological diagnosis with EUS-FNA when differentiation is difficult with diagnostic imaging has been reported [32].

\subsection{Pancreatic metastasis}

Metastatic pancreatic tumors are relatively rare, and their imaging findings vary depending on the primary lesion. Renal cell carcinoma is the most common primary tumor of pancreatic metastasis. Metastatic pancreatic tumors from renal cell carcinoma become hypervascular tumors and show imaging findings similar to those of PNENs. Although a history of renal cell carcinoma is useful information, these tumors are difficult to distinguish using imaging alone, and pathological histological diagnosis is required [33].

\section{Role of EUS-FNA in PNENs}

Tissue diagnosis and malignancy diagnosis with EUS-FNA are crucial for PNENs. Typical NETs need to be differentiated from SCNs, SPNs, and hypervascular pancreatic metastases, and atypical NETs, G3, and neuroendocrine carcinomas (NECs) need to be differentiated from normal pancreatic cancer and acinar cell carcinoma. These discriminations are difficult with diagnostic imaging alone, and tissue diagnosis plays a crucial role. The sensitivity and specificity of EUS-FNA for the diagnosis 
of PNENs are reported to be $73.2 \%-100 \%$ and $83.3 \%-93 \%$, respectively [34-37]. Hijioka et al. reported that the location of the tumor in the pancreatic head and the presence of rich stromal fibrosis negatively affects the sampling adequacy of EUS-FNA [38]. In recent years, fine-needle biopsy (FNB) needles have been used, which are expected to improve the diagnostic ability [39-45].

\subsection{Grading diagnosis}

The grading of PNENs according to the World Health Organization (WHO) pathological classification (G1, G2, G3, and NEC according to the mitotic index and Ki-67 index) is essential for determining the treatment strategy. NEC in the WHO 2010 classification has been subdivided into G3 and NEC in the WHO 2017 classification [46]. The treatment greatly differs between G3 and NEC.

In recent years, studies have shown that low-grade neuroendocrine neoplasms with a small diameter can be followed up without surgery [47-49]. As described above, the grading diagnosis is important for developing appropriate treatment strategies. The grading diagnosis requires the Ki67 index or mitotic index. Mitoses should be counted in 50 high-power fields (HPFs, $0.2 \mathrm{~mm}^{2}$ ) in areas of higher density and expressed as number per $10 \mathrm{HPFs}\left(2.0 \mathrm{~mm}^{2}\right)$. However, it is almost impossible to count in $50 \mathrm{HPFs}$ with FNA samples, and the Ki-67 proliferation index is usually used in clinical practice. The concordance rate of the Ki-67 index between PNENs measured from EUS-FNA samples and surgical specimens was reported to be $54 \%-100 \%$ [37,43-45,49-67] (Table 1), whereas a systematic review reported a rate of $83 \%$ [68]. Pooling the data of the studies which compared the Ki-67 LI grades obtained both in EUS-FNA samples and surgical specimen, the concordance rate was $77.5 \%$ and the kappa correlation index was 0.65 (95\% confidence interval $=0.59-0.71, \mathrm{P}<0.01)$ (Table 2) $[37,43-45,49$ $52,54-66,69]$. The sensitivity of G1 was good at $91.4 \%$ (338/370), but it was poor in G2 / G3 at 55.7\% and $59.5 \%$, respectively. The cause of this discrepancy was identified to be intratumoral heterogeneity of Ki-67, and hot spots (areas with the highest fraction of positive tumor cells) were not obtained. It is recommended to count $>2000$ cells to improve the grading diagnosis by EUS-FNA [70], and the WHO recommends counting $>500$ cells from hot spots. It has also been reported that increased tumor size may contribute to increased intratumoral heterogeneity [56,58]. Therefore, it is necessary to obtain as many tumor cells from as wide a range as possible when performing EUS-FNA in large PNENs. The use of the fanning technique and the FNB needle as the puncture needle may be good strategies for improving the diagnostic rate. 
Table 1. Previous reports showing the concordance rates between EUS-FNAB specimens and surgical specimens.

\begin{tabular}{|c|c|c|c|c|c|}
\hline First Author & year & study design & $\begin{array}{l}\text { Number of patients analyzed for } \\
\text { the concordance rate, } n\end{array}$ & $\begin{array}{c}\text { Ki-67 } \\
\text { concordance rate }\end{array}$ & Needle \\
\hline Piani C [49] & 2008 & retrospective & 18 & $78-89 \%$ a & 22-, or 25- gauge EUS-FNA needles \\
\hline Kaklamatos M [50] & 2011 & retrospective & 26 & $54 \%$ & NA \\
\hline Larghi A [51] & 2012 & prospective & 12 & $83.3 \%$ & 19- gauge EUS-FNA needles \\
\hline Hasegawa T [52] & 2014 & retrospective & 27 & $77.8 \%$ & $25-$, or 22- gauge EUS-FNA needles \\
\hline Weynand B [53] & 2014 & retrospective & 33 & $57.6 \%$ & 22- gauge EUS-FNA needles \\
\hline Carlinfante G [54] & 2014 & retrospective & 53 & $86.8 \%$ & $\begin{array}{c}25-, 19-, \text { or 22- gauge EUS-FNA or EUS-FNB } \\
\text { needles }\end{array}$ \\
\hline Farrell JM [55] & 2014 & retrospective & 22 & $86 \%$ & $\begin{array}{c}25-, 22-, \text { or 19- gauge needles (details } \\
\text { unknown) }\end{array}$ \\
\hline Unno J [56] & 2014 & retrospective & 19 & $89.5 \%$ & 22- gauge EUS-FNA needles \\
\hline Sugimoto M [57] & 2015 & retrospective & 8 & $87.5 \%$ & $25-, 22-$, or $19-$ gauge EUS-FNA needles \\
\hline Fujimori N [58] & 2016 & retrospective & 13 & $69.2 \%$ & $25-$, or 22 - gauge EUS-FNA needles \\
\hline Díaz Del Arco C [59] & 2016 & retrospective & 10 & $70 \%$ & NA \\
\hline Laskiewicz L [60] & 2018 & retrospective & 26 & $84.6 \%$ & NA \\
\hline Boutsen L [61] & 2018 & retrospective & 57 & $72 \%$ & NA \\
\hline Weiss VL [62] & 2018 & retrospective & 49 & $61 \%$ & NA \\
\hline Hwang HS [43] & 2018 & retrospective & 33 & $75.8 \%$ & 25-, 22-, or 19- gauge EUS-FNB needles \\
\hline Grosse C [63] & 2019 & retrospective & 15 & $100 \%$ & NA \\
\hline Di Leo M [44] & 2019 & retrospective & 25 & $84 \%$ & $\begin{array}{l}\text { 25- or 22- gauge EUS-FNA or 25-gauge EUS- } \\
\text { FNB needles }\end{array}$ \\
\hline Cui Y [64] & 2020 & retrospective & 37 & $73 \%$ & $\begin{array}{c}\text { 25-, 22-, or 19- gauge needles (details } \\
\text { unknown) }\end{array}$ \\
\hline Heidsma CM [37] & 2020 & retrospective & 63 & $81 \%$ & NA \\
\hline Kalantri S [65] & 2020 & retrospective & $6^{\mathrm{b}}$ & $100 \%$ b & 22- gauge needles (details unknown) \\
\hline Paiella S [66] & 2020 & prospective & 77 & $81.8 \%$ & 25-gauge EUS- FNA needle \\
\hline Kamata K [45] & 2020 & prospective & 23 & $82.6 \%$ & 25-gauge EUS- FNB needle \\
\hline
\end{tabular}


Table 2. Concordance of PNEN grading between EUS-FNAB specimens and surgical specimens in pooling data [37,43-45,49-52,54-66,69].

\begin{tabular}{ccccc}
\hline & \multicolumn{3}{c}{ Resected Tumor Grade } \\
\cline { 2 - 4 } EUS-FNAB Tumor Grade & Grade 1 & Grade 2 & Grade 3 & Total \\
\hline Grade 1 & 338 & 88 & 5 & 431 \\
Grade 2 & 32 & 111 & 12 & 155 \\
Grade 3 & 0 & 0 & 23 & 23 \\
Total & 370 & 199 & 40 & 609 \\
\hline
\end{tabular}

\section{Conclusion}

In the diagnosis of PNENs, EUS is especially useful for identifying small lesions. CE-EUS is also feasible to use for the evaluation of malignancy. EUS-FNA is useful not only for the definite diagnosis of PNENs but also for grading malignancy. EUS is a particularly important modality for the treatment of PNENs.

Author Contributions: Writing - original draft preparation, T.I.; writing - review and editing, T.I.; supervision, A.K.; project administration, A.K. All authors have read and agreed to the published version of the manuscript.

Funding: This research received no external funding.

Conflicts of Interest: A.K. received honoraria as lecture fee from Olympus Co., Tokyo Japan. The other authors declare no conflicts of interest relevant to this article.

\section{References}

1. Rösch, T.; Lightdale, C.J.; Botet, J.F.; Boyce, G.A.; Sivak, M.V., Jr.; Yasuda, K.; Heyder, N.; Palazzo, L.; Dancygier, H.; Schusdziarra, V.; et al. Localization of pancreatic endocrine tumors by endoscopic ultrasonography. N. Engl. J. Med. 1992, 326, 1721-1726, doi: 10.1056/NEJM199206253262601; PMID: 1317506.

2. Puli, S.R.; Kalva, N.; Bechtold, M.L.; Pamulaparthy, S.R.; Cashman, M.D.; Estes, N.C.; Pearl, R.H.; Volmar, F.H.; Dillon, S.; Shekleton, M.F.; et al. Diagnostic accuracy of endoscopic ultrasound in pancreatic neuroendocrine tumors: a systematic review and meta analysis. World J. Gastroenterol. 2013, 19, 3678-3684, doi: 10.3748/wjg.v19.i23.3678; PMID: 23801872; PMCID: PMC3691045.

3. Manta, R.; Nardi, E.; Pagano, N.; Ricci, C.; Sica, M.; Castellani, D.; Bertani, H.; Piccoli, M.; Mullineris, B.; Tringali, A.; et al. Pre-operative diagnosis of pancreatic neuroendocrine tumors with endoscopic ultrasonography and computed tomography in a large series. J. Gastrointestin. Liver Dis. 2016, 25, 317-321, doi: 10.15403/jgld.2014.1121.253.ned; PMID: 27689195.

4. Khashab, M.A.; Yong, E.; Lennon, A.M.; Shin, E.J.; Amateau, S.; Hruban, R.H.; Olino, K.; Giday, S. Fishman, E.K.; Wolfgang, C.L.; et al. EUS is still superior to multidetector computerized tomography for detection of pancreatic neuroendocrine tumors. Gastrointest. Endosc. 2011, 73, 691-696, doi: 10.1016/j.gie.2010.08.030, Epub 2010 Nov 10; PMID: 21067742.

5. James, P.D.; Tsolakis, A.V.; Zhang, M.; Belletrutti, P.J.; Mohamed, R.; Roberts, D.J.; Heitman, S.J. Incremental benefit of preoperative EUS for the detection of pancreatic neuroendocrine tumors: a metaanalysis. Gastrointest. Endosc. 2015, 81, 848-856.e1, doi: 10.1016/j.gie.2014.12.031; PMID: 25805462.

6. Ito, T.; Igarashi, H.; Nakamura, K.; Sasano, H.; Okusaka, T.; Takano, K.; Komoto, I.; Tanaka, M.; Imamura, M.; Jensen, R.T.; et al. Epidemiological trends of pancreatic and gastrointestinal neuroendocrine tumors in Japan: a nationwide survey analysis. J. Gastroenterol. 2015, 50, 58-64, doi: 10.1007/s00535-014-0934-2, Epub 2014 Feb 6; PMID: 24499825.

7. Lewis, R.B.; Lattin, G.E., Jr.; Paal, E. Pancreatic endocrine tumors: radiologic-clinicopathologic correlation. Radiographics 2010, 30, 1445-1464, doi: 10.1148/rg.306105523; PMID: 21071369.

8. Falconi, M.; Eriksson, B.; Kaltsas, G.; Bartsch, D.K.; Capdevila, J.; Caplin, M.; Kos-Kudla, B.; Kwekkeboom, D.; Rindi, G.; Klöppel, G. et al. ENETS consensus guidelines update for the management of patients with functional pancreatic neuroendocrine tumors and non-functional pancreatic neuroendocrine tumors. Neuroendocrinology 2016, 103, 153-171, doi: 10.1159/000443171, Epub 2016 Jan 5; PMID: 26742109; PMCID: PMC4849884. 
9. Tamagno, G.; Scherer, V.; Caimo, A.; Bergmann, S.R; Kann, P.H. Endoscopic Ultrasound Features of Multiple Endocrine Neoplasia Type 1-Related versus Sporadic Pancreatic Neuroendocrine Tumors: A Single-Center Retrospective Study. Digestion 2018, 98, 112-118, doi: 10.1159/000487939. Epub 2018 Apr 26. PMID: 29698969.

10. Kappelle, W.F.; Valk, G.D.; Leenders, M.; Moons, L.M.; Bogte, A.; Siersema, P.D.; Vleggaar, F.P. Growth rate of small pancreatic neuroendocrine tumors in multiple endocrine neoplasia type 1: results from an endoscopic ultrasound based cohort study. Endoscopy. 2017 Jan;49(1):27-34. doi: 10.1055/s-0042-119402. Epub 2016 Dec 14. PMID: 27975336.

11. Ishikawa, T.; Itoh, A.; Kawashima, H.; Ohno, E.; Matsubara, H.; Itoh, Y.; Nakamura, Y.; Nakamura, M.; Miyahara, R.; Hayashi, K.; et al. Usefulness of EUS combined with contrast-enhancement in the differential diagnosis of malignant versus benign and preoperative localization of pancreatic endocrine tumors. Gastrointest. Endosc. 2010, 71, 951-959, doi: 10.1016/j.gie.2009.12.023; PMID: 20438884.

12. Kitano, M.; Kudo, M.; Yamao, K.; Takagi, T.; Sakamoto, H.; Komaki, T.; Kamata, K.; Imai, H.; Chiba, Y.; Okada, M.; et al. Characterization of small solid tumors in the pancreas: the value of contrast-enhanced harmonic endoscopic ultrasonography. Am. J. Gastroenterol. 2012, 107, 303-310, doi: 10.1038/ajg.2011.354, Epub 2011 Oct 18; PMID: 22008892.

13. Palazzo, M.; Napoléon, B.; Gincul, R.; Pioche, M.; Pujol, B.; Lefort, C.; Fumex, F.; Hautefeuille, V.; Fabre, M.; Cros, J.; et al. Contrast harmonic EUS for the prediction of pancreatic neuroendocrine tumor aggressiveness (with videos). Gastrointest. Endosc. 2018, 87, 1481-1488, doi: 10.1016/j.gie.2017.12.033, Epub 2018 Jan 8; PMID: 29325706.

14. Takada, S.; Kato, H.; Saragai, Y.; Muro, S.; Uchida, D.; Tomoda, T.; Matsumoto, K.; Horiguchi, S.; Tanaka, N.; Okada, H. Contrast-enhanced harmonic endoscopic ultrasound using time-intensity curve analysis predicts pathological grade of pancreatic neuroendocrine neoplasm. J. Med. Ultrason. (2001) 2019, 46, 449458, doi: 10.1007/s10396-019-00967-x, Epub 2019 Aug 3; PMID: 31377939.

15. Kamata, K.; Takenaka, M.; Omoto, S.; Miyata, T.; Minaga, K.; Yamao, K.; Imai, H.; Sakurai, T.; Nishida, N.; Chikugo, T.; et al. Impact of avascular areas, as measured by contrast-enhanced harmonic EUS, on the accuracy of FNA for pancreatic adenocarcinoma. Gastrointest. Endosc. 2018, 87, 158-163, doi: 10.1016/j.gie.2017.05.052, Epub 2017 Jun 12; PMID: 28619244

16. Gaujoux, S.; Tang, L.; Klimstra, D.; Gonen, M.; Brennan, M.F.; D'Angelica, M.; DeMatteo, R.; Fong, Y.; Jarnagin, W.; Allen, P.J. The outcome of resected cystic pancreatic endocrine neoplasms: a case-matched analysis. Surgery 2012, 151, 518-525, doi: 10.1016/j.surg.2011.09.037, Epub 2011 Nov 16; PMID: 22088817.

17. Imaoka, H.; Yamao, K.; Salem, A.A.; Sawaki, A.; Takahashi, K.; Mizuno, N.; Kawai, H.; Tajika, M.; Isaka, T.; Okamoto, Y.; et al. Pancreatic endocrine neoplasm can mimic serous cystadenoma. Int. J. Gastrointest. Cancer 2005, 35, 217-220, doi: 10.1385/IJGC:35:3:217; PMID: 16110124.

18. Dhaliwal, A.J.S.; Strosberg, J.R.; Centeno, B.A.; Vignesh, S. Diagnostic performance of endoscopic ultrasound-guided fine-needle aspiration for cystic and non-cystic pancreatic neuroendocrine tumors. Endosc Int Open. 2019 Jul;7(7):E854-E859. doi: 10.1055/a-0915-9496. Epub 2019 Jul 3. PMID: 31286055; PMCID: PMC6611730.

19. Li-Geng, T.; Cai, G.; Aslanian, H.R. EUS diagnosis of cystic pancreatic neuroendocrine tumors. VideoGIE. 2018, 3(3), 106. doi: 10.1016/j.vgie.2017.12.007. PMID: 29916484; PMCID: PMC6004037.

20. McCall, C.M.; Shi, C.; Klein, A.P.; Konukiewitz, B.; Edil, B.H.; Ellison, T.A.; Wolfgang, C.L.; Schulick, R.D.; Klöppel, G.; Hruban, R.H. Serotonin expression in pancreatic neuroendocrine tumors correlates with a trabecular histologic pattern and large duct involvement. Hum. Pathol. 2012, 43, 1169-1176, doi: 10.1016/j.humpath.2011.09.014, Epub 2012 Jan 4; PMID: 22221702; PMCID: PMC3323730.

21. Kiyonaga, M.; Matsumoto, S.; Mori, H.; Yamada, Y.; Takaji, R.; Hijiya, N.; Yoshizumi, F.; Aramaki, M. Pancreatic neuroendocrine tumor with extensive intraductal invasion of the main pancreatic duct: a case report. JOP 2014, 15, 497-500, doi: 10.6092/1590-8577/2741; PMID: 25262720.

22. Luo, Y.; Dong, Z.; Chen, J.; Chan, T.; Lin, Y.; Chen, M.; Li, Z.P.; Feng, S.T. Pancreatic neuroendocrine tumours: correlation between MSCT features and pathological classification. Eur. Radiol. 2014, 24, 29452952, doi: 10.1007/s00330-014-3317-4, Epub 2014 Jul 22; PMID: 25048189.

23. d'Assignies, G.; Couvelard, A.; Bahrami, S.; Vullierme, M.P.; Hammel, P.; Hentic, O.; Sauvanet, A.; Bedossa, P.; Ruszniewski, P.; Vilgrain, V. Pancreatic endocrine tumors: tumor blood flow assessed with perfusion CT reflects angiogenesis and correlates with prognostic factors. Radiology 2009, 250, 407-416, doi: 10.1148/radiol.2501080291, Epub 2008 Dec 18; PMID: 19095784. 
24. Hanada, K.; Kurihara, K.; Itoi, T.; Katanuma, A.; Sasaki, T.; Hara, K.; Nakamura, M.; Kimura, W.; Suzuki, Y.; Sugiyama, M.; et al. Clinical and pathological features of solid pseudopapillary neoplasms of the pancreas: a nationwide multicenter study in Japan. Pancreas 2018, 47, 1019-1026, doi: 10.1097/MPA.0000000000001114; PMID: 30059473.

25. Liu, Y.; Shi, S.; Hua, J.; Xu, J.; Zhang, B.; Liu, J.; Yang, X.J.; Yu, X.J. Differentiation of solid-pseudopapillary tumors of the pancreas from pancreatic neuroendocrine tumors by using endoscopic ultrasound. Clin. Res. Hepatol. Gastroenterol. 2020, S2210-7401(20)30035-8, doi: 10.1016/j.clinre.2020.02.002, Epub ahead of print; PMID: 32144073.

26. Fujii, M.; Saito, H.; Kato, H.; Kojima, T.; Ito, M.; Ishiyama, S.; Fujiwara, A.; Niguma, T.; Yoshioka, M.; Shiode, J.; et al. Diagnosis of a solid pseudopapillary neoplasm using EUS-FNA. Intern. Med. 2013, 52, 17031708, doi: 10.2169/internalmedicine.52.0238, Epub 2012 Mar 1; PMID: 23903503.

27. Ardengh, J.C.; Lopes, C.V.; Venco, F.E.; Machado, M.A. Diagnosis of pancreatic solid pseudopapillary neoplasms using cell-blocks and immunohistochemical evaluation of endoscopic ultrasound-guided fine needle aspiration biopsy specimens. Cytopathology 2020, doi: 10.1111/cyt.12905, Epub ahead of print; PMID: 32816310.

28. Park, H.S.; Kim, S.Y.; Hong, S.M.; Park, S.H.; Lee, S.S.; Byun, J.H.; Kim, J.H.; Kim, H.J.; Lee, M.G. Hypervascular solid-appearing serous cystic neoplasms of the pancreas: Differential diagnosis with neuroendocrine tumours. Eur. Radiol. 2016, 26, 1348-1358, doi: 10.1007/s00330-015-3961-3, Epub 2015 Sep 2; PMID: 26328927.

29. Bhutiani, N.; Egger, M.E.; Doughtie, C.A.; Burkardt, E.S.; Scoggins, C.R.; Martin, R.C., 2nd; McMasters, K.M. Intrapancreatic accessory spleen (IPAS): a single-institution experience and review of the literature. Am. J. Surg. 2017, 213, 816-820, doi: 10.1016/j.amjsurg.2016.11.030, Epub 2016 Nov 23; PMID: 27894508.

30. Kim, G.E.; Morris, J.D.; Anand, N.; DePalma, F.; Greenwald, B.D.; Kim, R.E.; Laczek, J.; Lee, W.J.; Papadopoulas, I.; Uradomo, L.; et al. Recognizing intrapancreatic accessory spleen via EUS: interobserver variability. Endosc. Ultrasound 2019, 8, 392-397, doi: 10.4103/eus.eus_35_19; PMID: 31417068; PMCID: PMC6927143.

31. Bhutani, M.S.; Singh, B.S.; Cazacu, I.M.; Saftoiu, A. Differentiating intrapancreatic accessory spleen from a pancreatic neuroendocrine tumor or metastasis by the "bridge sign". Endosc. Ultrasound 2019, 8, 281-282, doi: 10.4103/eus.eus_29_19; PMID: 31249165; PMCID: PMC6714477.

32. Renno, A.; Hill, M.; Abdel-Aziz, Y.; Meawad, H.; Lenhard, A.; Nawras, A. Diagnosis of intrapancreatic accessory spleen by endoscopic ultrasound-guided fine-needle aspiration mimicking a pancreatic neoplasm: a case report and review of literature. Clin. J. Gastroenterol. 2020, 13, 287-297, doi: 10.1007/s12328019-01045-y

33. Fabbri, C.; Luigiano, C.; Maimone, A.; Tarantino, I.; Baccarini, P.; Fornelli, A.; Liotta, R.; Polifemo, A.; Barresi, L.; Traina, M.; et al. Endoscopic ultrasound-guided fine-needle biopsy of small solid pancreatic lesions using a 22-gauge needle with side fenestration. Surg. Endosc. 2015, 29, 1586-1590, doi:10.1007/s00464-014-3846-6.

34. Ito, T.; Hijioka, S.; Masui, T.; Kasajima, A.; Nakamoto, Y.; Kobayashi, N.; Komoto, I.; Hijioka, M.; Lee, L.; Igarashi, H.;.et al. Advances in the diagnosis and treatment of pancreatic neuroendocrine neoplasms in Japan. J. Gastroenterol. 2017, 52, 9-18, doi:10.1007/s00535-016-1250-9.

35. Chen, S.; Lin, J.; Wang, X.; Wu, H.H.; Cramer, H. EUS-guided FNA cytology of pancreatic neuroendocrine tumour (PanNET): a retrospective study of 132 cases over an 18-year period in a single institution. Cytopathology 2014, 25, 396-403, doi:10.1111/cyt.12137.

36. Krishna, S.G.; Bhattacharya, A.; Li, F.; Ross, W.A.; Ladha, H.; Porter, K.; Atiq, M.; Bhutani, M.S.; Lee, J.H. Diagnostic differentiation of pancreatic neuroendocrine tumor from other neoplastic solid pancreatic lesions during endoscopic ultrasound-guided fine-needle aspiration. Pancreas 2016, 45, 394-400, doi: 10.1097/MPA.0000000000000488; PMID: 26418912.

37. Heidsma, C.M.; Tsilimigras, D.I.; Rocha, F.; Abbott, D.E.; Fields, R.; Smith, P.M.; Poultsides, G.A.; Cho, C.; van Eijck, C.; van Dijkum, E.N.; et al. US Neuroendocrine Tumor Study Group. Clinical relevance of performing endoscopic ultrasound-guided fine-needle biopsy for pancreatic neuroendocrine tumors less than 2 cm. J Surg Oncol. 2020 Aug 11. doi: 10.1002/jso.26158. Epub ahead of print. PMID: 32783272.

38. Hijioka, S.; Hara, K.; Mizuno, N.; Imaoka, H.; Bhatia, V.; Mekky, M.A.; Yoshimura, K.; Yoshida, T.; Okuno, N.; Hieda, N.; et al. Diagnostic performance and factors influencing the accuracy of EUS-FNA of pancreatic 
neuroendocrine neoplasms. J. Gastroenterol. 2016, 51, 923-930, doi: 10.1007/s00535-016-1164-6, Epub 2016 Jan 14; PMID: 26768605; PMCID: PMC4990623.

39. Hedenström, P. The best approach for sampling of pancreatic neuroendocrine tumors - EUS-FNA or EUSFNB? Endosc. Int. Open 2019, 7, E1400-E1402, doi:10.1055/a-0959-6138.

40. Eusebi, L.H.; Thorburn, D.; Toumpanakis, C.; Frazzoni, L.; Johnson, G.; Vessal, S.; Luong, T.V.; Caplin, M.; Pereira, S.P. Endoscopic ultrasound-guided fine-needle aspiration vs fine-needle biopsy for the diagnosis of pancreatic neuroendocrine tumors. Endosc. Int. Open 2019, 7, E1393-E1399, doi: 10.1055/a-0967-4684, Epub 2019 Oct 22; PMID: 31673610; PMCID: PMC6805236.

41. Witt, B.L.; Factor, R.E.; Chadwick, B.E.; Caron, J.; Siddiqui, A.A.; Adler. D.G. Evaluation of the SharkCore ${ }^{\circledR}$ needle for EUS-guided core biopsy of pancreatic neuroendocrine tumors. Endosc. Ultrasound 2018, 7, 323328, doi: 10.4103/eus.eus_51_17; PMID: 29623910; PMCID: PMC6199904.

42. Leeds, J.S.; Nayar, M.K.; Bekkali, N.; Wilson, C.H.; Johnson, S.J.; Haugk, B.; Darne, A.; Oppong, K.W. Endoscopic ultrasound-guided fine-needle biopsy is superior to fine-needle aspiration in assessing pancreatic neuroendocrine tumors. Endosc Int Open. 2019;7(10):E1281-E1287. doi:10.1055/a-0990-9611

43. Hwang, H.S.; Kim, Y.; An, S.; Kim, S.J.; Kim, J.Y.; Kim, S.Y.; Hwang, D.W.; Park, D.H.; Lee, S.S.; Kim, S.C.; et al. Grading by the Ki-67 Labeling Index of Endoscopic Ultrasound-Guided Fine Needle Aspiration Biopsy Specimens of Pancreatic Neuroendocrine Tumors Can Be Underestimated. Pancreas. 2018 Nov/Dec;47(10):1296-1303. doi: 10.1097/MPA.0000000000001157. PMID: 30211805.

44. Di Leo, M.; Poliani, L.; Rahal, D.; Auriemma, F.; Anderloni, A.; Ridolfi, C.; Spaggiari, P.; Capretti, G.; Di Tommaso, L.; Preatoni P.; et al. Pancreatic Neuroendocrine Tumours: The Role of Endoscopic Ultrasound Biopsy in Diagnosis and Grading Based on the WHO 2017 Classification. Dig Dis 2019;37:325-333. doi: 10.1159/000499172. Epub 2019 Mar 21. PMID: 30897588.

45. Kamata, K.; Ashida, R.; Yasukawa, S.; Chiba, Y.; Fukutake, N.; Nebiki, H.; Kurita, A.; Takaoka, M.; Ogura, T.; Shiomi, H.; et al. Histological diagnosis and grading of pancreatic neuroendocrine tumor by endoscopic ultrasound-guided fine needle biopsy using a 25-gauge needle with a core trap: A multicenter prospective trial. Pancreatology. 2020 Oct;20(7):1428-1433. doi: 10.1016/j.pan.2020.08.023. Epub 2020 Sep 12. PMID: 32952043.

46. Lloyd, R.V.; Osamura, R.Y.; Klöppel, G.; Rosai, J., Eds. WHO Classification of Tumours of Endocrine Organs, 4th ed.; IARC Press: Lyon, France, 2017.

47. Lee, L.C.; Grant, C.S.; Salomao, D.R.; Fletcher, J.G.; Takahashi, N.; Fidler, J.L.; Levy, M.J.; Huebner, M.; Small, nonfunctioning, asymptomatic pancreatic neuroendocrine tumors (PNETs): role for nonoperative management. Surgery. 2012 Dec;152(6):965-74. doi: 10.1016/j.surg.2012.08.038. Epub 2012 Oct 24. PMID: 23102679.

48. Kurita, Y.; Hara, K.; Kuwahara, T.; Mizuno, N.; Okuno, N.; Haba, S.; Okuno, M.; Natsume, S.; Senda, Y.; Kubota, K.; et al. Comparison of prognosis between observation and surgical resection groups with small sporadic non-functional pancreatic neuroendocrine neoplasms without distant metastasis. J. Gastroenterol. 2020, 55, 543-552, doi: 10.1007/s00535-019-01655-w, Epub 2019 Dec 19; PMID: 31858231.

49. Piani, C.; Franchi, G.M.; Cappelletti, C.; Scavini, M.; Albarello, L.; Zerbi, A.; Giorgio Arcidiacono, P.; Bosi, E.; Manzoni, M.F. Cytological Ki-67 in pancreatic endocrine tumours: an opportunity for pre-operative grading. Endocr Relat Cancer. 2008 Mar;15(1):175-81. doi: 10.1677/ERC-07-0126. PMID: 18310285.

50. Kaklamanos, M.; Karoumpalis, I.; Salla, C.; Thomas, D.; Kanakis, G.; Alexandraki, K.; Sougioultzis, S.; Diakatou, E.; Kontogeorgos, G.; Kaltsas, G. Diagnostic accuracy and clinical significance of the fine needle aspiration Ki-67 labelling index in pancreatic endocrine tumours. Endocr Relat Cancer. 2011 Oct 27;18(6):L1-3. doi: 10.1530/ERC-10-0191. PMID: 22034543.

51. Larghi, A.; Capurso, G.; Carnuccio, A.; Ricci, R.; Alfieri, S.; Galasso, D.; Lugli, F.; Bianchi, A.; Panzuto, F.; De Marinis, L.; et al. Ki-67 grading of nonfunctioning pancreatic neuroendocrine tumors on histologic samples obtained by EUS-guided fine-needle tissue acquisition: a prospective study. Gastrointest. Endosc. 2012, 76, 570-577, doi: 10.1016/j.gie.2012.04.477. Erratum in: Gastrointest. Endosc. 2012, 76, 1085; PMID: 22898415.

52. Hasegawa, T.; Yamao, K.; Hijioka, S.; Bhatia, V.; Mizuno, N.; Hara, K.; Imaoka, H.; Niwa, Y.; Tajika, M.; Kondo, S.; et al. Evaluation of Ki-67 index in EUS-FNA specimens for the assessment of malignancy risk in pancreatic neuroendocrine tumors. Endoscopy 2014, 46, 32-38, doi: 10.1055/s-0033-1344958, Epub 2013 Nov 11; PMID: 24218309. 
53. Weynand, B.; Borbath, I.; Bernard, V.; Sempoux, C.; Gigot, J.F.; Hubert, C.; Lannoy, V.; Deprez, P.H.; JouretMourin, A. Pancreatic neuroendocrine tumour grading on endoscopic ultrasound-guided fine needle aspiration: high reproducibility and inter-observer agreement of the Ki-67 labelling index. Cytopathology 2014, 25, 389-395, doi: 10.1111/cyt.12111, Epub 2013 Nov 15; PMID: 24750272.

54. Carlinfante, G.; Baccarini, P.; Berretti, D.; Cassetti, T.; Cavina, M.; Conigliaro, R.; De Pellegrin, A.; Di Tommaso, L.; Fabbri, C.; Fornelli, A.; et al. Ki-67 cytological index can distinguish well-differentiated from poorly differentiated pancreatic neuroendocrine tumors: a comparative cytohistological study of 53 cases. Virchows Arch. 2014 Jul;465(1):49-55. doi: 10.1007/s00428-014-1585-7. Epub 2014 May 8. PMID: 24807732.

55. Farrell, J.M.; Pang, J.C.; Kim, G.E.; Tabatabai, Z.L. Pancreatic neuroendocrine tumors: accurate grading with Ki-67 index on fine-needle aspiration specimens using the WHO 2010/ENETS criteria. Cancer Cytopathol. 2014, 122, 770-778, doi: 10.1002/cncy.21457, Epub 2014 Jul 9; PMID: 25044931.

56. Unno, J.; Kanno, A.; Masamune, A.; Kasajima, A.; Fujishima, F.; Ishida, K.; Hamada, S.; Kume, K.; Kikuta, K.; Hirota, M.; et al. The usefulness of endoscopic ultrasound-guided fine-needle aspiration for the diagnosis of pancreatic neuroendocrine tumors based on the World Health Organization classification. Scand. J. Gastroenterol. 2014, 49, 1367-1374, doi: 10.3109/00365521.2014.934909, Epub 2014 Sep 2; PMID: 25180490.

57. Sugimoto, M.; Takagi, T.; Hikichi, T.; Suzuki, R.; Watanabe, K.; Nakamura, J.; Kikuchi, H.; Konno, N.; Waragai, Y.; Asama, H.; et al. Efficacy of endoscopic ultrasonography-guided fine needle aspiration for pancreatic neuroendocrine tumor grading. World J Gastroenterol. 2015 Jul 14;21(26):8118-24. doi: 10.3748/wjg.v21.i26.8118. PMID: 26185384; PMCID: PMC4499355.

58. Fujimori, N.; Osoegawa, T.; Lee, L.; Tachibana, Y.; Aso, A.; Kubo, H.; Kawabe, K.; Igarashi, H.; Nakamura, K.; Oda, Y.; et al. Efficacy of endoscopic ultrasonography and endoscopic ultrasonography-guided fineneedle aspiration for the diagnosis and grading of pancreatic neuroendocrine tumors. Scand. J. Gastroenterol. 2016, 51, 245-252, doi: 10.3109/00365521.2015.1083050, Epub 2015 Sep 11; PMID: 26513346.

59. Díaz Del Arco, C.; Díaz Pérez, J.Á.; Ortega Medina, L.; Sastre Valera, J.; Fernández Aceñero, M.J. Reliability of Ki-67 Determination in FNA Samples for Grading Pancreatic Neuroendocrine Tumors. Endocr Pathol. 2016 Dec;27(4):276-283. doi: 10.1007/s12022-016-9455-2. PMID: 27688080.

60. Laskiewicz, L.; Jamshed, S.; Gong, Y.; Ainechi, S.; LaFemina, J.; Wang, X. The diagnostic value of FNA biopsy in grading pancreatic neuroendocrine tumors. Cancer Cytopathol. 2018 Mar;126(3):170-178. doi: 10.1002/cncy.21956. Epub 2017 Dec 19. PMID: 29266776.

61. Boutsen, L.; Jouret-Mourin, A.; Borbath, I.; van Maanen, A.; Weynand, B. Accuracy of Pancreatic Neuroendocrine Tumour Grading by Endoscopic Ultrasound-Guided Fine Needle Aspiration: Analysis of a Large Cohort and Perspectives for Improvement. Neuroendocrinology. 2018;106(2):158-166. doi: 10.1159/000477213. Epub 2017 May 12. PMID: 28494461.

62. Weiss, V.L.; Kiernan, C.; Wright, J.; Merchant, N.B.; Coogan, A.C.; Shi, C. Fine-Needle Aspiration-Based Grading of Pancreatic Neuroendocrine Neoplasms Using Ki-67: Is Accurate WHO Grading Possible on Cytologic Material? J Am Soc Cytopathol. 2018 May-Jun;7(3):154-459. doi: 10.1016/j.jasc.2018.02.001. Epub 2018 Feb 13. PMID: 30038894; PMCID: PMC6054317.

63. Grosse, C.; Noack, P.; Silye, R. Accuracy of grading pancreatic neuroendocrine neoplasms with Ki-67 index in fine-needle aspiration cellblock material. Cytopathology. 2019 Mar;30(2):187-193. doi: 10.1111/cyt.12643. Epub 2018 Nov 28. PMID: 30303569.

64. Cui, Y.; Khanna, L.G.; Saqi, A.; Crapanzano, J.P.; Mitchell, J.M.; Sethi, A.; Gonda, T.A.; Kluger, M.D.; Schrope, B.A.; Allendorf, J.; et al. The role of endoscopic ultrasound-guided Ki67 in the management of non-functioning pancreatic neuroendocrine tumors. Clin. Endosc. 2020, 53, 213-220, doi: 10.5946/ce.2019.068, Epub 2019 Jul 15; PMID: 31302988; PMCID: PMC7137561.

65. Kalantri, S.; Bakshi, P.; Verma, K. Grading of pancreatic neuroendocrine tumors on endoscopic ultrasoundguided fine-needle aspiration using Ki-67 index and 2017 World Health Organization criteria: An analysis of 32 cases. Cytojournal. 2020 Sep 18;17:21. doi: 10.25259/Cytojournal_4_2020. PMID: 33093857; PMCID: PMC7568229.

66. Paiella, S.; Landoni, L.; Rota, R.; Valenti, M.; Elio, G.; Crinò, SF.; Manfrin, E.; Parisi, A.; Cingarlini, S.; D'Onofrio, M.; et al. Endoscopic ultrasound-guided fine-needle aspiration for the diagnosis and grading of pancreatic neuroendocrine tumors: a retrospective analysis of 110 cases. Endoscopy. 2020 Nov;52(11):988994. doi: 10.1055/a-1180-8614. Epub 2020 Jun 4. PMID: 32498099. 
67. Rebours, V.; Cordova, J.; Couvelard, A.; Fabre, M.; Palazzo, L.; Vullierme, M.P.; Hentic, O.; Sauvanet, A.; Aubert, A.; Bedossa, P.; et al.. Can pancreatic neuroendocrine tumour biopsy accurately determine pathological characteristics? Dig Liver Dis. 2015 Nov;47(11):973-7. doi: 10.1016/j.dld.2015.06.005. Epub 2015 Jun 20. PMID: 26169284.

68. Pezzilli, R.; Partelli, S.; Cannizzaro, R.; Pagano, N.; Crippa, S.; Pagnanelli, M.; Falconi, M. Ki-67 prognostic and therapeutic decision driven marker for pancreatic neuroendocrine neoplasms (PNENs): a systematic review. Adv. Med. Sci. 2016, 61, 147-153, doi: 10.1016/j.advms.2015.10.001, Epub 2015 Oct 23; PMID: 26774266.

69. Tatsumoto, S.; Kodama, Y.; Sakurai, Y.; Shinohara, T.; Katanuma, A.; Maguchi, H. Pancreatic neuroendocrine neoplasm: correlation between computed tomography enhancement patterns and prognostic factors of surgical and endoscopic ultrasound-guided fine-needle aspiration biopsy specimens. Abdom Imaging. 2013 Apr;38(2):358-66. doi: 10.1007/s00261-012-9953-8. PMID: 22945422.

70. Perren, A.; Couvelard, A.; Scoazec, J.Y.; Costa, F.; Borbath, I.; Delle Fave, G.; Gorbounova, V.; Gross, D.; Grossma, A.; Jense, R.T.; et al. ENETS consensus guidelines for the standards of care in neuroendocrine tumors: pathology: diagnosis and prognostic stratification. Neuroendocrinology 2017, 105, 196-200, doi: 10.1159/000457956, Epub 2017 Feb 11; PMID: 28190015. 